\title{
Synthesis and Photophysical Properties of Butterfly-shaped Dinuclear Pt(II) complex having NHC-based Chelate Ligands.
}

Sangjoon Moon ${ }^{\mathrm{a}}$, Shinnosuke Horiuchi ${ }^{\mathrm{a}}$, Eri Sakuda ${ }^{\mathrm{a}}$, Akitaka Ito ${ }^{\mathrm{b}}$, Yasuhiro Arikawa ${ }^{\mathrm{a}}$, Keisuke Umakoshi ${ }^{\mathrm{a}^{*}}$

${ }^{a}$ Division of Chemistry and Materials Science, Graduate School of Engineering, Nagasaki University, Bunkyo-machi, Nagasaki 852-8521, Japan.

${ }^{\mathrm{b}}$ Graduate School of Engineering, Kochi University of Technology, 185, Miyanokuchi, Tosayamada, Kami, Kochi 782-1502, Japan

\begin{abstract}
A butterfly-shaped dinuclear Pt(II) complex having pyridyl-NHC chelate ligands and bridging $\mathrm{Me}_{2} \mathrm{pz}$ ligands was synthesized. The crystal structure of the $\mathrm{Pt}_{2}$ complex showed

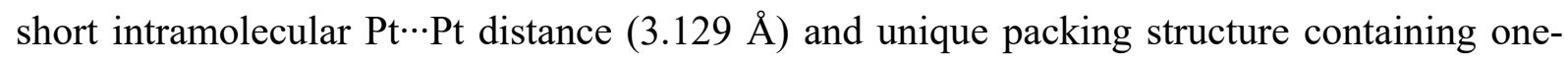
dimensional infinite pore that was filled with solvent molecules. The absorbance was proportional to the concentration of $\mathrm{Pt}_{2}$ complex and no significant bands appeared even in high concentration (up to $100 \mu \mathrm{M}$ ). The $\mathrm{Pt}_{2}$ complex showed blue color emission $\left(\lambda_{\max }=459 \mathrm{~nm}\right)$ in the solid state at $298 \mathrm{~K}\left(\lambda_{\mathrm{ex}}=330 \mathrm{~nm}\right)$. TD-DFT calculation revealed that the lowest-energy absorption bands are mainly assigned to the combination of metal-to-ligand charge transfer (MLCT) and ligand-to-ligand charge transfer (LLCT) transitions.
\end{abstract}

Keywords: Pyridyl-NHC ligand; Dinuclear complex; Platinum.

*Corresponding author. Tel./fax: +81958192672

E-mail address: kumks@nagasaki-u.ac.jp (K. Umakoshi)

\section{Introduction}

Luminescent square-planer $\mathrm{Pt}(\mathrm{II})$ complexes have been increasingly studied as photocatalysts [1], emitting materials [2], and chemical sensors [3]. Some luminescent Pt(II) complexes show intermolecular Pt $\cdots$ Pt interactions in the solid state and in concentrated solutions, incorporating characteristic photophysical properties, such as aggregation-induced emission (AIE) [4] and white-colored dual emission [5]. Their emissive states are attributed to a variety of low-energy excited states depending on the nature of $\pi$-type ligands and the extent of intermolecular metal-metal interactions. The tuning of intramolecular Pt $\cdots P t$ distances in dinuclear Pt(II) complexes have been achieved by careful selection of substituent groups on the bridging pyrazolate ligands, exhibiting unique photophysical properties in solutions [6]. 
The Pt(II) complexes having chelating $N$-heterocyclic carbene (NHC) ligands such as phenyl-NHC [7], bis-NHC [8] and pyridyl-NHC [9] have recently been developed as luminescent materials owing to their attractive features. They are expected to show bright emission, because strong $\sigma$-donating nature of carbene ligands effectively destabilizes unoccupied 5d-orbital of $\mathrm{Pt}(\mathrm{II})$ ion and in conjunction with phenyl, NHC or pyridyl moiety it also destabilizes the LUMO [10]. Another advantage of chelating NHC ligands is bidentate coordination to the central metal ion, which can endow them with thermal stability in the structure. These rigid and robust complexes are likely to show desirable luminescent properties due to effective inhibition of thermal nonradiative pathways. Therefore, Pt(II) complexes having chelating carbene ligands are widely used to develop luminescent materials showing blue emission.

We have reported structures and emission properties of heteropolynuclear $\mathrm{Pt}(\mathrm{II})$ complexes supported by pyrazolate bridging ligands [11]. These heteropolynuclear complexes consist of Pt(II) and group 11 metal ions and are usually prepared from mononuclear $\mathrm{Pt}(\mathrm{II})$ complexes having pyrazole and/or pyrazolate acting as monodentate ligands. Moreover, butterfly-shaped PtPd complex can also be prepared from the mononuclear Pt(II) complex containing bipyrimidine chelate ligand and dimethylpyrazole (Me2pzH) [11c]. The mononuclear $\mathrm{Pt}(\mathrm{II})$ complexes containing $\mathrm{N}^{\wedge} \mathrm{N}, \mathrm{N}^{\wedge} \mathrm{C}$ or $\mathrm{C}^{\wedge} \mathrm{C}$ chelate ligands and pyrazoles have tendency to form butterfly-shaped dinuclear Pt(II) complexes due to their lower thermal stability. In the course of preparation of heteropolynuclear $\mathrm{Pt}(\mathrm{II})$ complex having pyridyl-NHC chelate ligands [11g], we also encountered the formation of butterfly-shaped dinuclear Pt(II) complex.

It is known that employment of NHC carbene donor leads to a significant increase in the LUMO energy, and consequently increases the relative emission energy for the corresponding Ir(III) complexes [12]. The pyridyl-NHC chelate ligand is one of the strong $\sigma$-donating neutral ligand, which delocalizes less electron density on $\mathrm{Pt}$ atom compared with $\mathrm{C}^{\wedge} \mathrm{N}$ chelate ligands possessing negative charge such as 2-phenylpyridinate (ppy). Therefore, the dinuclear $\mathrm{Pt}(\mathrm{II})$ complexes having pyridyl-NHC chelate ligands are expected to show higher-energy emissions than those having ppy and its derivatives due to weaker Pt $\cdots P$ Pt interactions. They are also expected to show unique photophysical properties derived from intra- and inter-molecular $\mathrm{Pt} \cdots \mathrm{Pt}$ interactions [13]. Herein we report the selective synthesis and photophysical properties of butterfly-shaped dinuclear Pt(II) complex having pyridyl-NHC chelate ligands and bridging Merpz ligands.

\section{Results and Discussion}




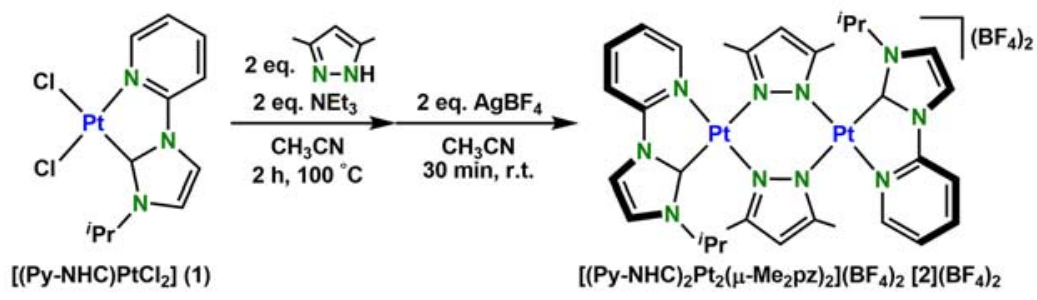

Scheme 1. Synthesis of $\left[\left(\mathrm{Py}-\mathrm{NHC}_{2}\right)_{2} \mathrm{Pt}_{2}\left(\mu-\mathrm{Me}_{2} \mathrm{pz}_{2}\right]\left(\mathrm{BF}_{4}\right)_{2}\left([2]\left(\mathrm{BF}_{4}\right)_{2}\right)\right.$

(a)

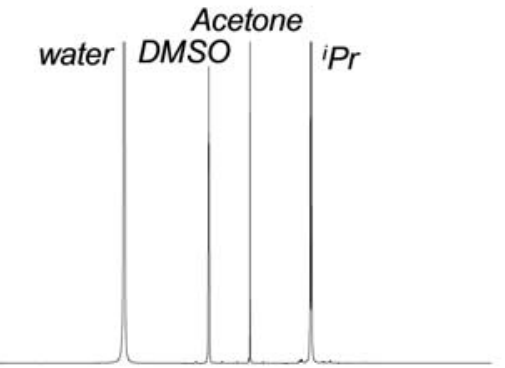

(b)

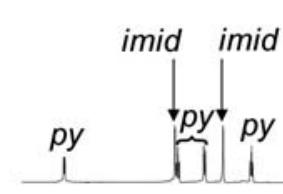

${ }^{i} \mathrm{Pr}$

water $\quad M e(p z)$

Acetone

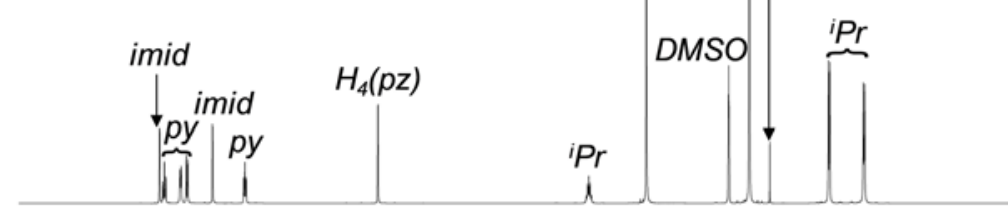

(c) imid imid

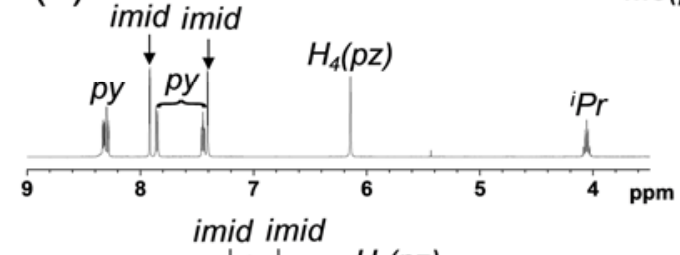

$\mathrm{Me}(\mathrm{pz}) \neg$ water

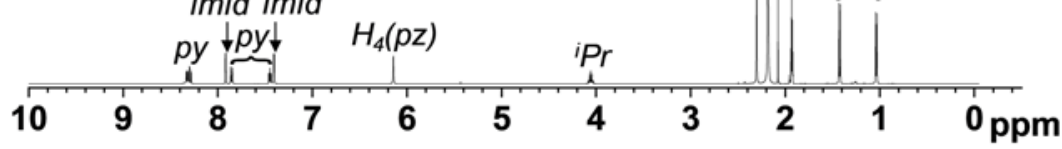

Fig. 1. ${ }^{1} \mathrm{H}$ NMR spectra (500 MHz, r.t.) of (a) 1 in DMSO-d6, (b) $[2]\left(\mathrm{BF}_{4}\right)_{2}$ in DMSO-d $d_{6}$ and (c) $[2]\left(\mathrm{BF}_{4}\right)_{2}$ in $\mathrm{CD}_{3} \mathrm{CN}$.

The butterfly-shaped $\mathrm{Pt}_{2}$ complex was synthesized by refluxing the mixture of [(Py$\mathrm{NHC} \mathrm{PtCl}_{2}$ ] (1) and 3,5-dimethylpyrazole $\left(\mathrm{Me}_{2} \mathrm{pzH}\right)$ in acetonitrile for $2 \mathrm{~h}$ at $100{ }^{\circ} \mathrm{C}$ in the presence of triethylamine under air. After a counter anion exchange reaction with $\mathrm{AgBF}_{4}$, the $\mathrm{BF}_{4}$ salt, $\left[(\mathrm{Py}-\mathrm{NHC})_{2} \mathrm{Pt}_{2}\left(\mu-\mathrm{Me}_{2} \mathrm{pz}_{2}\right]\left(\mathrm{BF}_{4}\right)_{2}\left([2]\left(\mathrm{BF}_{4}\right)_{2}\right)\right.$, was isolated as a white solid in $46 \%$ yield (Scheme 1). The reaction was followed by ${ }^{1} \mathrm{H}$ NMR spectroscopy. The ${ }^{1} \mathrm{H}$ NMR spectrum of $[2]\left(\mathrm{BF}_{4}\right)_{2}$ showed single sets of the signals corresponding to the pyridyl-NHC ligands and the bridging $\mathrm{Me}_{2} \mathrm{pz}$ ligand (Fig. 1). It also exhibited two doublet signals corresponding to diastereotopic isopropyl substituents. Additionally, upfield shifts $(\Delta \delta=-1 \sim-2$ ppm) of pyridine protons and isopropyl protons were observed due to the shielding effect of pyrazolate 
ligands. These results strongly support the formation of $[2]^{2+}$. Electrospray ionization mass spectroscopy (ESI-MS) clearly revealed the formation of [2](BF4)2 at $\mathrm{m} / \mathrm{z} 1041.3$ which was assigned to $\left[2+\left(\mathrm{BF}_{4}\right)\right]^{+}$fragments.
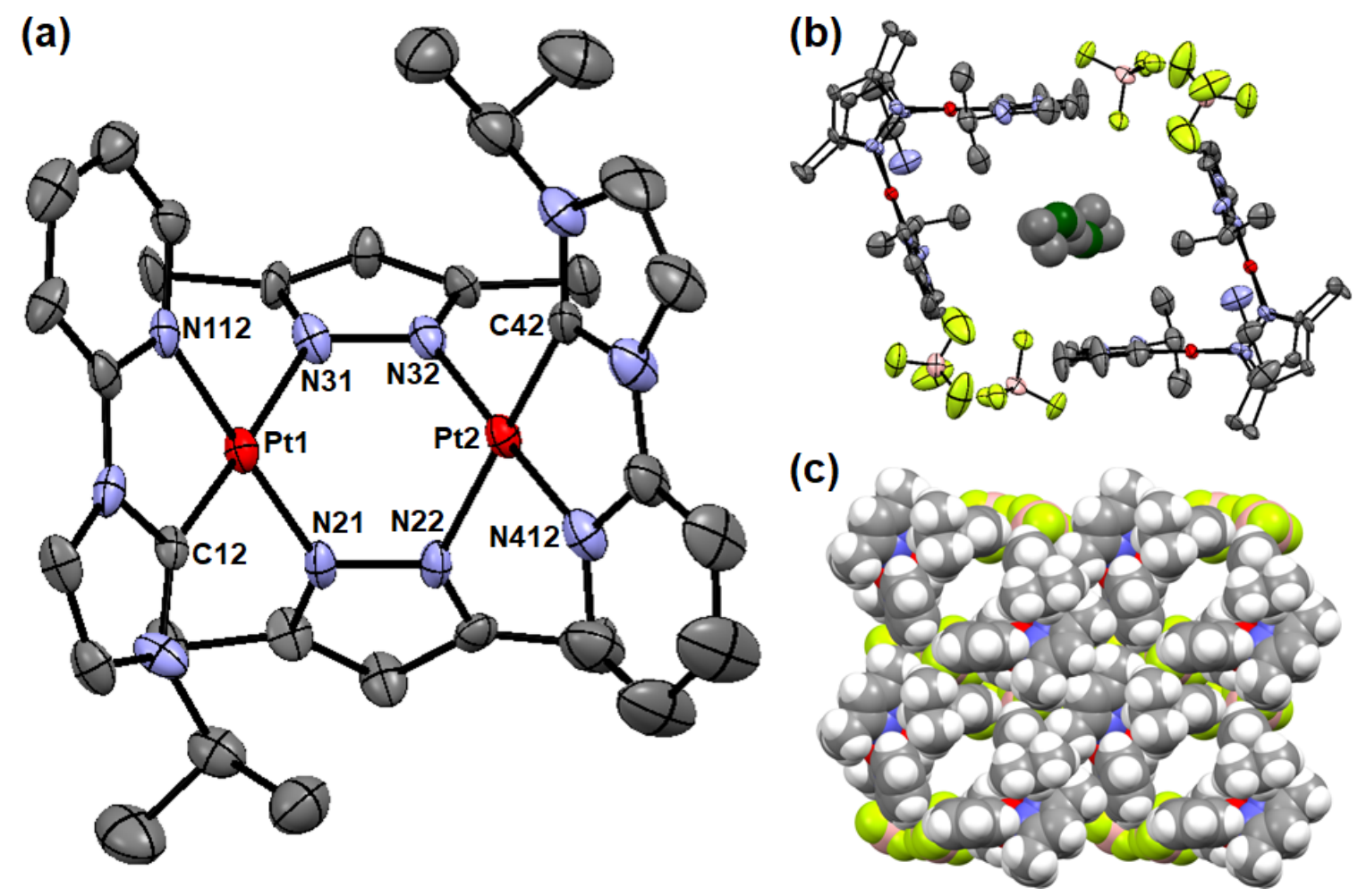

Fig. 2. (a) ORTEP representation (50\% probability ellipsoids) of $[2]^{2+}$. Hydrogen atoms are omitted for clarity. (b, c) Packing diagram of [2] $\left(\mathrm{BF}_{4}\right)_{2}$ and diethyl ether (solvent molecule). Solvent molecules are trapped in the infinite one-dimensional pore constructed by butterfly-

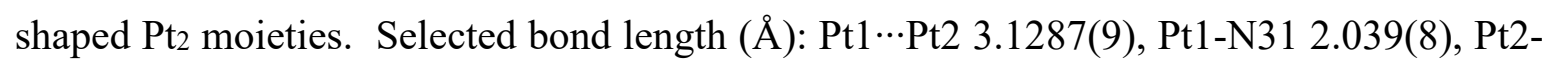
N32 2.010(8), Pt1-N21 2.006(8), Pt2-N22 2.061(8), Pt1-N112 2.029(8), Pt2-N412 2.011(9), Pt1-C12 1.963(9), Pt2-C42 1.961(10).

The molecular structure of $[2]\left(\mathrm{BF}_{4}\right) 2$ was confirmed by single crystal X-ray structural analysis (Fig. 2). A single crystal suitable for X-ray crystallographic analysis was obtained from $\mathrm{CH}_{3} \mathrm{CN} / \mathrm{Et}_{2} \mathrm{O}$ solution. Similarly to analogous butterfly-shaped $\mathrm{Pt}_{2}$ complexes having bridging pyrazolate ligands [6], the complex cation $[2]^{2+}$ also had the butterfly-shaped structure with

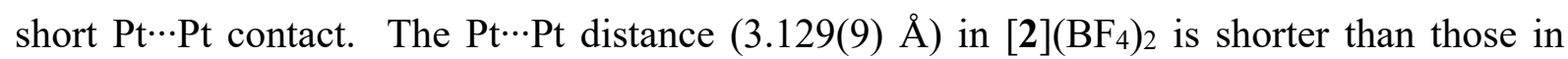
$\left[\mathrm{Pt}_{2}(\mathrm{ppy})_{2}\left(\mu-\mathrm{Me}_{2} \mathrm{pz}\right)_{2}\right]$ (3) (ppy = 2-phenylpyridinate) (3.1904(13) $\AA$ ) [6e] and $\left[\mathrm{Pt}_{2}(\mathrm{bpym})_{2}(\mu-\right.$ $\left.\left.\mathrm{Me}_{2} \mathrm{pz}\right)_{2}\right]\left([4]\left(\mathrm{PF}_{6}\right)_{2}\right)\left(\right.$ bpym $=2,2^{\prime}$-bipyrimidine $)(3.1968(7) \AA)$ [11c] and the sum of the van der Waals radius of Pt atom (3.5 $\AA$ ). The Pt1-N31 and Pt2-N22 distances trans to Pt-C $\mathrm{C}_{\mathrm{NHC}}$ bonds are approximately $0.04 \AA$ longer than the Pt1-N21 and Pt2-N32 distances trans to the Pt- $\mathrm{N}_{\mathrm{py}}$ bonds. These differences in Pt-N bond lengths resulted from stronger trans influence of carbene 
carbon atom in NHC moiety. The single crystal of [2](BF4) 2 has interesting packing structure containing infinite one dimensional pore which is fulfilled by diethyl ether (Fig. $2 b$ and $2 c$ ). The diethyl ether molecule and the counter anions $\left(\mathrm{BF}_{4}^{-}\right)$locate between two complex cations, $[2]^{2+}$, suggesting no intermolecular Pt $\cdots \mathrm{Pt}$ interaction in the single crystal state. Unfortunately the single crystal of $[2]\left(\mathrm{BF}_{4}\right)_{2}$ easily loses solvent molecules from crystal lattice, leading to the crystalline-to-amorphous transformation (Fig. S6). It indicates that the one-dimensional infinite pore cannot be preserved after losing solvent molecules from crystal lattice.

The UV/Vis absorption spectra of $[2]\left(\mathrm{BF}_{4}\right)_{2}$ recorded in $\mathrm{CH}_{3} \mathrm{CN}$ at room temperature showed the lowest-energy absorption bands at $342 \mathrm{~nm}$, which are higher in energy than those of ppy analogue 3 (377 nm) [6b] and bpym analogue [4](PF6)2 (388 nm) (Fig. 3a) [11c]. These results well reflect the differences in charge and $\sigma$-donating nature of chelate ligand (vide infra). The absorbance was proportional to the concentration of $\mathrm{Pt}_{2}$ complex and no significant bands appeared even in high concentration (up to $100 \mu \mathrm{M}$ ), indicating that the intermolecular Pt $\cdots \mathrm{Pt}$ interactions are weak or negligible in solution.

The $\mathrm{Pt}_{2}$ complex [2] $\left(\mathrm{BF}_{4}\right)_{2}$ encouraged us to investigate photoluminescence in solution, because ppy analogue 3 shows photo-induced structural changes by shortening of $\mathrm{Pt} \cdots \mathrm{Pt}$ distance and tunable dual emission in solution [6d]. However, we found that $[2]\left(\mathrm{BF}_{4}\right)_{2}$ was non-emissive in solution. Similar feature was also observed in bpym analogue $[4]\left(\mathrm{PF}_{6}\right)_{2}\left(\Phi_{\mathrm{em}}\right.$ $=0.05 \%$ in $\mathrm{CH}_{3} \mathrm{CN}$ ) [11c]. Possibly, the cationic nature of $[2]^{2+}$ readily induced solvent association for the photo-induced excited species, resulting in mainly thermal nonradiative pathways in solution. In contrast to the non-emissive nature in solution, [2] $\left(\mathrm{BF}_{4}\right)_{2}$ showed bluish-green emission ( $\lambda_{\mathrm{em}}=459 \mathrm{~nm}$ ) with moderate quantum yield at room temperature in the solid state $\left(\Phi_{\mathrm{em}}=2 \%, \lambda_{\mathrm{ex}}=330 \mathrm{~nm}\right)$ (Fig. 3b). Time-resolved emission lifetime measurements
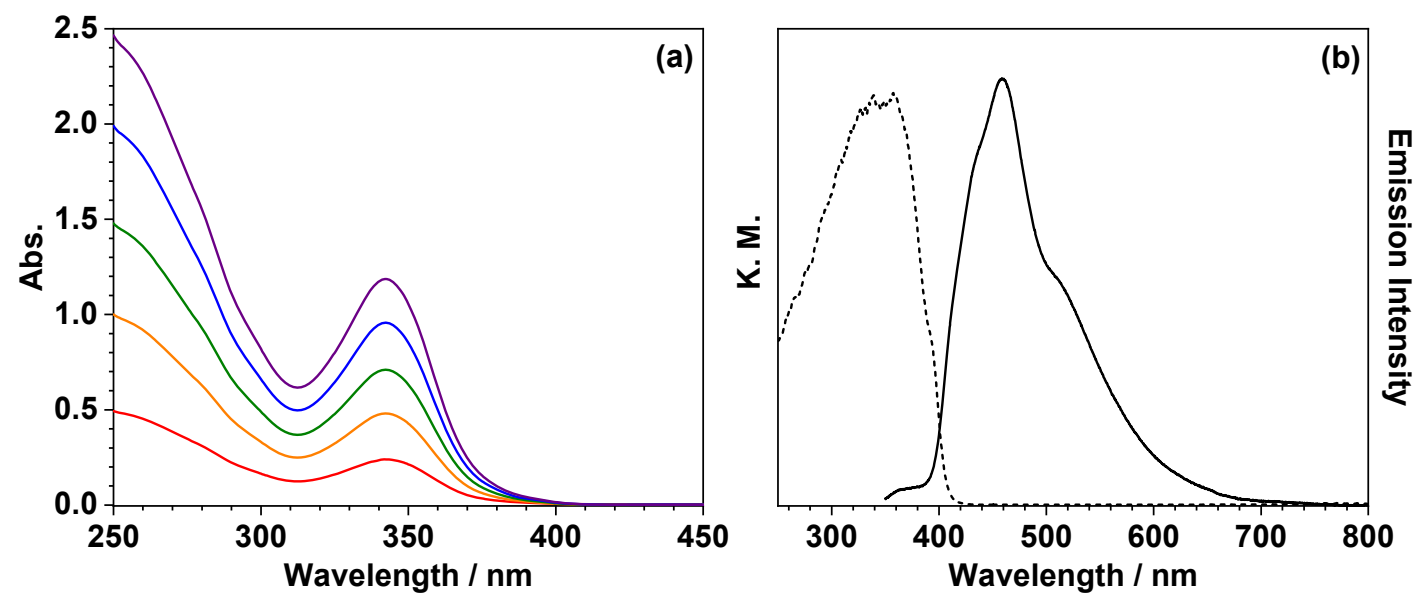

Fig. 3. (a) $\mathrm{UV} / \mathrm{Vis}$ absorption spectra of $[2]\left(\mathrm{BF}_{4}\right)_{2}$ in $\mathrm{CH}_{3} \mathrm{CN}$ (red line: $20 \mu \mathrm{M}$, orange line: $40 \mu \mathrm{M}$, green line: $60 \mu \mathrm{M}$, blue line: $80 \mu \mathrm{M}$, purple line: $100 \mu \mathrm{M}$ ). (b) Diffuse reflectance spectrum (broken line) and emission spectrum (solid line) of $[2]\left(\mathrm{BF}_{4}\right)_{2}$ in the solid state $\left(\lambda_{\mathrm{ex}}\right.$ $=330 \mathrm{~nm})$. 
revealed the phosphorescence originated from triplet-excited state with the lifetimes of microsecond regime $\left(\tau_{1}=0.60 \mu \mathrm{s}\left(\mathrm{A}_{1}=0.90\right), \tau_{2}=3.81 \mu \mathrm{s}\left(\mathrm{A}_{2}=0.10\right), \tau_{\mathrm{ave}}=1.9 \mu \mathrm{s}\right)$.

To shed light on the absorption spectrum of $[2]\left(\mathrm{BF}_{4}\right)_{2}$, the absorption bands were theoretically investigated with the time-dependent density functional theory (TD-DFT) method (Figs. 4 and S7, Tables S1 and S3). It revealed that the highest-occupied molecular orbital (HOMO) is located on $\pi$-orbital of pyrazolate ligands and $5 \mathrm{~d}$ orbitals of Pt atoms (Table S3), and the HOMO-1 is manly located on $5 \mathrm{~d}$ orbitals of Pt atoms. On the contrary, the lowestunoccupied molecular orbital (LUMO) is mainly located on $\pi^{*}$-orbital of Py-NHC chelate ligands and 5d orbitals of the Pt atoms contribute to LUMO slightly. Thus, the lowest-energy absorption bands are mainly assigned to the electronic transitions from $\mathrm{S}_{0}$ to $\mathrm{S}_{1}$ state (HOMO-1 $\rightarrow$ LUMO and HOMO $\rightarrow$ LUMO), which are the combination of metal-to-ligand charge transfer (MLCT) and ligand-to-ligand charge transfer (LLCT) transitions.

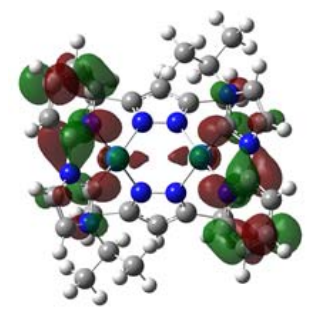

LUMO

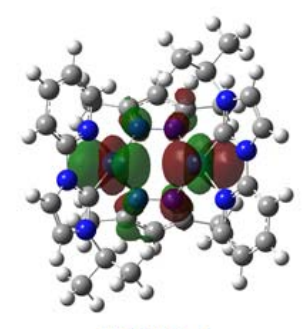

HOMO-1
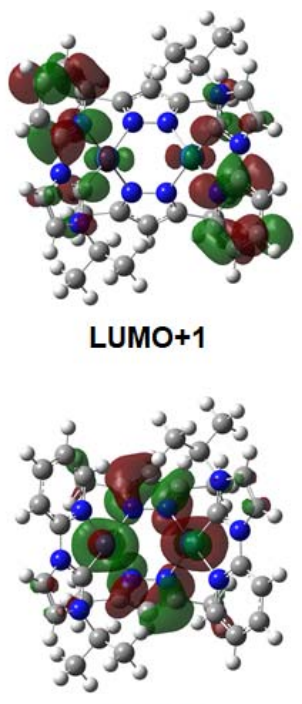

HOMO

Fig. 4. Molecular orbitals important to the band assignment for $[2]^{2+}$ by the B3LYP method.

As mentioned above, $[2]\left(\mathrm{BF}_{4}\right)_{2}$ showed bluish-green emission $\left(\lambda_{\mathrm{em}}=459 \mathrm{~nm}\right)$ in the solid state, which is higher in energy than that of $3\left(\lambda_{\mathrm{em}}=525 \mathrm{~nm}\right)[6 \mathrm{~d}]$. This is in contrast to the observation that the intramolecular Pt...Pt distance in $[2]\left(\mathrm{BF}_{4}\right)_{2}$ is shorter than that in 3. To unveil the origin of the differences in the photophysical properties of $[2]\left(\mathrm{BF}_{4}\right)_{2}$ and $\mathbf{3}$, we performed additional DFT calculations on the triplet excited state for $[2]^{2+}$ as well as the singlet and triplet excited states for 3 (Tables S2, S5 and S6). As shown in Figure 5, the energy difference between $\mathrm{d} \sigma$ and $\mathrm{d}^{*}$ in $[2]^{2+}(\Delta E=0.92 \mathrm{eV})$ is smaller than that in $\mathbf{3}(\Delta E=1.07 \mathrm{eV})$, indicating that the destabilization of $d \sigma^{*}$ orbital in $[2]^{2+}$ is smaller than that in $\mathbf{3}$. This may be 
attributed to the difference of charge on the $\mathrm{C}^{\wedge} \mathrm{N}$ chelate ligands (neutral Py-NHC ligand vs. negative ppy ligand), which correlates to the electron density on the metal centers $(+0.776$ for $[2]^{2+},+0.610$ for 3 (Fig. S8)). The calculated energies of emission based on the crystal structures of $[2]\left(\mathrm{BF}_{4}\right)_{2}$ and 3 [6e] in Tables S5 and S6, respectively, also agree well with the experimental results described above. Therefore, the dinuclear Pt(II) complexes having pyridyl-NHC chelate ligands have potential as blue emitters.

(a)

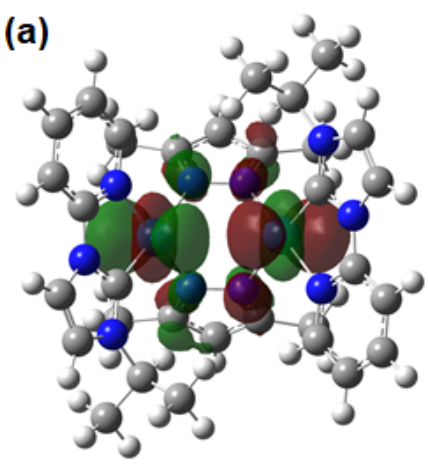

HOMO-1 (d $\left.\sigma^{*}\right)$

$-6.517 \mathrm{eV}$

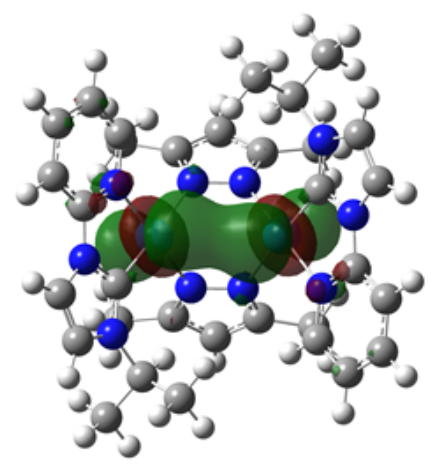

HOMO-7 (d $\sigma)$

$-7.435 \mathrm{eV}$ (b)
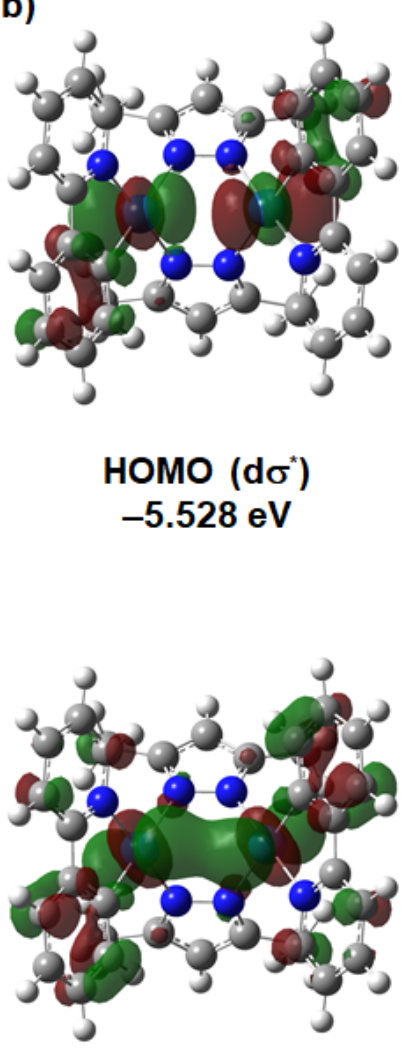

HOMO-9 (d $\sigma)$

$-6.600 \mathrm{eV}$

Fig. 5. Molecular orbitals of $d \sigma^{*}$ and $d \sigma$ and their energies for (a) $[2]^{2+}$ and (b) 3 .

\section{Conclusion}

In summary, we studied the effect of Py-NHC chelate ligand on the structure and photophysical properties of the butterfly-shaped dinuclear Pt(II) complex having Merpz bridging ligands. The single crystal X-ray analysis revealed that $[2]\left(\mathrm{BF}_{4}\right)_{2}$ has infinite one dimensional pore in the crystal lattice. The intramolecular Pt $\cdots P t$ distance in [2](BF4)2 (3.129(9) $\AA$ ) is shorter than those in analogous $\mathrm{Pt}_{2}$ complexes having Me $2 \mathrm{pz}$ bridging ligands. Although $[2]\left(\mathrm{BF}_{4}\right)_{2}$ did not show emission in solution, it showed bluish-green emission in the solid state at room temperature. The lowest-energy absorption bands are mainly assigned to the combination of MLCT and LLCT transitions. This study gives an insight into the tuning of 
emission energy of butterfly-shaped $\mathrm{Pt}_{2}$ complexes having $\mathrm{C}^{\wedge} \mathrm{N}$ chelate ligands.

\section{Experimental}

\subsection{General}

All reactions and subsequent work-up manipulations were performed in air unless otherwise noted. Organic solvents and all other reagents were commercially available and used without further purification. The $1 \mathrm{D}\left({ }^{1} \mathrm{H},{ }^{13} \mathrm{C}\right)$ and $2 \mathrm{D}\left({ }^{1} \mathrm{H}-{ }^{1} \mathrm{H}\right.$ COSY, ${ }^{1} \mathrm{H}_{-}{ }^{13} \mathrm{C}$ HSQC, ${ }^{1} \mathrm{H}_{-}{ }^{13} \mathrm{C}$ HMBC) NMR spectra were obtained at $300 \mathrm{MHz}$ Varian Gemini 300 or $500 \mathrm{MHz}$ Varian NMR System 500PS spectrometer. UV/Vis spectra were recorded on a Jasco V-560 spectrophotometer at $20^{\circ} \mathrm{C}$. Diffuse reflectance spectrum was recorded on a Jasco V-670DS spectrophotometer at $20{ }^{\circ} \mathrm{C}$. The corrected emission spectrum was obtained by using a Hamamatsu PMA-12 multichannel photodetector (excitation wavelength $=355 \mathrm{~nm}$ ). Emission quantum yields in the solid state were determined by using a Hamamatsu Photonic Absolute PL Quantum Yield Measurement System C9920-02 with an integrating sphere and a PMA-12 multichannel photodetector (excitation wavelength $=300 \mathrm{~nm}$ ). The emission lifetime measurements were conducted by using a Hamamatsu C11200 streak camera as a photodetector by exciting at $355 \mathrm{~nm}$ using a nanosecond Q-switched Nd:YAG laser (Continum ${ }^{\circledR}$ Minilite $^{\mathrm{TM}}$, fwhm $\approx 10-12 \mathrm{~ns}$, repetition rate $=10 \mathrm{~Hz}$ ).

\subsection{Synthesis of 1-(2-pyridyl)-3-isopropylimidazolium iodide}

This ligand was prepared according to the literature methods [14,15] with slight modifications. A mixture of 2-bromopyridine (3.14 g, $20 \mathrm{mmol})$, imidazole $(4.1 \mathrm{~g}, 60 \mathrm{mmol})$ and $\mathrm{K}_{2} \mathrm{CO}_{3}(5.52 \mathrm{~g}, 40 \mathrm{mmol})$ was heated at $140{ }^{\circ} \mathrm{C}$ with stirring for 2 days. The reaction mixture was dissolved into $\mathrm{CH}_{2} \mathrm{Cl}_{2}$, and the solution was filtered. The filtrate was washed with water and concentrated under reduced pressure. The crude product was purified through silica gel column chromatography to give 1-(2-pyridyl)imidazole as colorless oil (2.17 g, 75\%). 1-(2pyridyl)imidazole (2.17 g, $14.94 \mathrm{mmol})$ was dissolved into 2-iodopropane (10 $\mathrm{mL})$ and the solution was heated at $100{ }^{\circ} \mathrm{C}$ with stirring for 24 hours. After diethyl ether was added to the reaction mixture, the resulted white precipitate was collected by filtration, washed with diethyl ether, and dried in vacuum. Yield $4.19 \mathrm{~g}(67 \%)$. ${ }^{1} \mathrm{H}$ NMR $\left(300 \mathrm{MHz}, \mathrm{CD}_{3} \mathrm{CN}, 25{ }^{\circ} \mathrm{C}\right): \delta=9.67(\mathrm{~s}, 1 \mathrm{H}$, imid), 8.58 (d, $J=4.8 \mathrm{~Hz}, 1 \mathrm{H}$, py), 8.18 (t, $J=1.9 \mathrm{~Hz}, 1 \mathrm{H}$, imid), 8.10 (ddd, $J=1.9,1.9,1.8$ Hz, 1H, py), 7.96 (d, $J=8.4 \mathrm{~Hz}, 1 \mathrm{H}, \mathrm{py}), 7.74$ (t, $J=2.0 \mathrm{~Hz}, 1 \mathrm{H}$, imid), 7.56 (dd, $J=4.9 \mathrm{~Hz}$, 1H, py), 4.82 (sept, $\left.J=6.9 \mathrm{~Hz}, 1 \mathrm{H},{ }^{i} \operatorname{Pr}\right), 1.60$ (d, $J=6.7 \mathrm{~Hz}, 6 \mathrm{H},{ }^{i} \mathrm{Pr}$ ).

\subsection{Preparation of [(Py-NHC) $\left.\mathrm{PtCl}_{2}\right](\mathbf{1})$}

This complex was prepared according to the literature method with slight modifications 
[16]. A mixture of 1-(2-pyridyl)-3-isopropylimidazolium iodide (779 $\mathrm{mg}, 2.47 \mathrm{mmol}$ ) and $\left[\mathrm{Pt}(\mathrm{COD}) \mathrm{Cl}_{2}\right](\mathrm{COD}=1,5$-cyclooctadiene $)(919 \mathrm{mg}, 2.46 \mathrm{mmol})$ in benzonitrile $(50 \mathrm{~mL})$ was heated at $130{ }^{\circ} \mathrm{C}$ with stirring for $24 \mathrm{~h}$. After concentration of the reaction mixture under reduced pressure, acetonitrile $(10 \mathrm{~mL})$ was added to the mixture and the solution was cooled at $4{ }^{\circ} \mathrm{C}$ for $12 \mathrm{~h}$. The yellow crystals were collected, washed with acetonitrile and diethyl ether, and dried in vacuum. Yield $768 \mathrm{mg}(63 \%)$. Anal. Calcd for $\mathrm{C}_{11} \mathrm{H}_{13} \mathrm{~N}_{3} \mathrm{Cl}_{2} \mathrm{Pt}$ : C, 29.20; H, 2.90; N, 9.29. Found: C, 29.27; H, 2.60; N, 9.75. ${ }^{1} \mathrm{H}$ NMR (500 MHz, DMSO- $\left.d_{6}, 25{ }^{\circ} \mathrm{C}\right): \delta=9.55$ (d, $J=6.1 \mathrm{~Hz}, 1 \mathrm{H}$, py), 8.38 (d, $J=2.1 \mathrm{~Hz}, 1 \mathrm{H}, \mathrm{imid}), 8.35$ (t, $J=7.6 \mathrm{~Hz}, 1 \mathrm{H}, \mathrm{py}), 8.07$ (d, $J=$ $8.6 \mathrm{~Hz}, 1 \mathrm{H}, \mathrm{py}), 7.87$ (d, $J=2.3 \mathrm{~Hz}, 1 \mathrm{H}, \mathrm{imid}), 7.57$ (t, $J=6.5 \mathrm{~Hz}, 1 \mathrm{H}, \mathrm{py}$ ), 6.06 (sept, $J=6.4$ $\left.\mathrm{Hz}, 1 \mathrm{H},{ }^{i} \mathrm{Pr}\right), 1.41\left(\mathrm{~d}, J=6.7 \mathrm{~Hz}, 6 \mathrm{H},{ }^{i} \mathrm{Pr}\right) .{ }^{13} \mathrm{C} \mathrm{NMR}\left(125 \mathrm{MHz}, \mathrm{DMSO}-d_{6}, 25{ }^{\circ} \mathrm{C}\right): \delta=152.7$, $148.3,142.7,141.7,123.1,120.7,117.4,112.3,50.3,22.7$.

\subsection{Preparation of $\left[(\mathrm{Py}-\mathrm{NHC})_{2} \mathrm{Pt}_{2}\left(\mu-\mathrm{Me}_{2} \mathrm{pz}\right)_{2}\right]\left(\mathrm{BF}_{4}\right)_{2}\left([2]\left(\mathrm{BF}_{4}\right)_{2}\right)$}

A mixture of [(Py-NHC) $\left.\mathrm{PtCl}_{2}\right]$ (1) (47 mg, $\left.0.11 \mathrm{mmol}\right), 3,5-\mathrm{Me}_{2} \mathrm{pzH}$ (26 mg, $\left.0.27 \mathrm{mmol}\right)$ and triethyl amine $(30 \mathrm{~mL}, 0.21 \mathrm{mmol})$ in acetonitrile $(5 \mathrm{~mL})$ was refluxed for $2 \mathrm{~h}$. After heating, $\mathrm{AgBF}_{4}(50.8 \mathrm{mg}, 0.26 \mathrm{mmol})$ was added to the reaction mixture and it was stirred for $30 \mathrm{~min}$ at room temperature. The reaction mixture was filtered to remove white precipitate $(\mathrm{AgCl})$. The filtrate was concentrated, and diethyl ether was added to the solution. The resulted white precipitate was collected, washed with water and diethyl ether, and dried in vacuum. Yield 28 mg (46\%). It was recrystallized from acetonitrile/diethyl ether. Anal. Calcd for $\mathrm{C}_{32} \mathrm{H}_{40} \mathrm{~N}_{10} \mathrm{~B}_{2} \mathrm{~F}_{8} \mathrm{Pt}_{2}$ : C, 34.03; H, 3.57; N, 12.41. Found: C, 34.43; H, 3.47; N, 12.75. ${ }^{1} \mathrm{H}$ NMR $\left(500 \mathrm{MHz}, \mathrm{CD}_{3} \mathrm{CN}, 25^{\circ} \mathrm{C}\right): \delta=8.33(\mathrm{~d}, J=5.8 \mathrm{~Hz}, 2 \mathrm{H}, \mathrm{py}), 8.30$ (ddd, $J=7.8,7.8,5.9 \mathrm{~Hz}$, 2H, py), 7.92 (d, $J=2.5 \mathrm{~Hz}, 2 \mathrm{H}$, imid), 7.85 (d, $J=8.3 \mathrm{~Hz}, 2 \mathrm{H}$, py), 7.45 (ddd, $J=5.9,5.9,1.2$ $\mathrm{Hz}, 2 \mathrm{H}, \mathrm{py}), 7.41$ (d, $J=2.4 \mathrm{~Hz}, 2 \mathrm{H}$, imid), 6.14 (s, 2H, pz), 4.06 (sept, $J=6.6 \mathrm{~Hz}, 2 \mathrm{H},{ }^{i} \mathrm{Pr}$ ), $2.30(\mathrm{~s}, 12 \mathrm{H}, \mathrm{pz}), 1.42\left(\mathrm{~d}, J=6.7 \mathrm{~Hz}, 6 \mathrm{H},{ }^{i} \mathrm{Pr}\right), 1.04\left(\mathrm{~d}, J=6.7 \mathrm{~Hz}, 6 \mathrm{H},{ }^{i} \mathrm{Pr}\right) .{ }^{13} \mathrm{C}$ NMR $(125$ $\left.\mathrm{MHz}, \mathrm{CD}_{3} \mathrm{CN}, 25^{\circ} \mathrm{C}\right): \delta=154.7,150.9,150.9,150.5,150.1,145.4,125.2,121.3,119.6,114.0$, 107.6, 31.4, 24.9, 22.7, 15.1, 14.0. ESIMS: $m / z$ 1041.3 $\left[M+\mathrm{BF}_{4}\right]^{+}$.

\subsection{X-ray structural analysis}

Single crystal of $[2]\left(\mathrm{BF}_{4}\right)_{2}$ suitable for X-ray crystallographic analysis was obtained by recrystallization from $\mathrm{CH}_{3} \mathrm{CN} /$ ether. Diffraction data were collected at $-180{ }^{\circ} \mathrm{C}$ under a stream of cold $\mathrm{N}_{2}$ gas on a Rigaku RA-Micro7 HFM instrument equipped with a Rigaku Saturn724+ $\mathrm{CCD}$ detector by using graphite-monochromated Mo-K $\alpha$ radiation. The frame data were integrated using a Rigaku CrystalClear program package, and the data sets were corrected for absorption using a REQAB program. The calculations were performed with a CrystalStructure software package [17]. The initial structure was solved by Patterson methods (DIRDIF99- 
PATTY) [18], and refined on $F^{2}$ by the full-matrix least squares methods. Anisotropic refinement was applied to all non-hydrogen atoms with the exception of the crystal solvents (SHELXL-2014/7) [19]. All hydrogen atoms were put at calculated positions.

Crystal data for $[2]\left(\mathrm{BF}_{4}\right)_{2} \cdot 0.5\left\{\left(\mathrm{C}_{2} \mathrm{H}_{5}\right)_{2} \mathrm{O}\right\}: \mathrm{C}_{36} \mathrm{H}_{48} \mathrm{~B}_{2} \mathrm{~F}_{8} \mathrm{~N}_{11} \mathrm{O}_{0.5} \mathrm{Pt}_{2}, M=1206.64$, space group $P-1$ (no. 2), $a=11.868(4), b=12.527(5), c=15.714(6) \AA, \alpha=106.359(6), \beta=92.480(5)$, $\gamma=91.760(5)^{\circ}, V=2237.2(14) \AA^{3}, Z=2, \rho_{\text {calcd }}=1.791 \mathrm{~g} / \mathrm{cm}^{3}, \mu(\mathrm{MoK} \alpha)=6.296 \mathrm{~mm}^{-1}, F(000)$ $=1166.0, T=93 \mathrm{~K}$, Reflections collected 15529, Independent reflections 7742 [ $\left.R_{\text {int }}=0.0395\right]$, Data/restraints/parameters 7742/10/535, Goodness-of-fit on $F^{2} 1.049$, Final R index $[I>2 \sigma(I)]$ $R_{1}=0.0504, R$ indices (all data) $R_{1}=0.0699, w R_{2}=0.1057$, Largest diff. peak and hole 1.37 and $-1.33\left(\mathrm{e} \AA^{-3}\right)$, CCDC number 1890891. Since the solvent molecules (diethyl ether) were disordered, they were refined isotropically on two positions. Restraints instructions (DFIX, SIMU) were applied in the treatment of the disorder.

\subsection{Measurement of emission spectrum.}

The corrected emission spectrum was recorded by using white powder sample of [2] $\left(\mathrm{BF}_{4}\right)_{2}$, which was obtained by evacuating single crystals at room temperature for $2 \mathrm{hrs}$. Emission spectrum of [2] $\left(\mathrm{BF}_{4}\right)_{2}$ in the solid state was obtained by using a Hamamatsu PMA-12 multichannel photodetector (excitation wavelength $=355 \mathrm{~nm}$ ) and a nanosecond Q-switched Nd:YAG laser $\left(\right.$ Continum ${ }^{\circledR}$ Minilite $^{\mathrm{TM}}$, fwhm $\approx 10-12 \mathrm{~ns}$, repetition rate $=10 \mathrm{~Hz}$ ) at $20{ }^{\circ} \mathrm{C}$.

\subsection{Computational methods.}

Ground-state geometries of the complexes were optimized by using the B3LYP density functional theory (DFT). X-ray structures were used as initial geometries without any geometrical constraints. The LanL2DZ and $6-31 G(d, p)$ basis sets were used to treat the platinum and all other atoms, respectively. Time-dependent (TD)-DFT calculations were then performed to estimate the energies and oscillator strengths $f$ of the lowest-energy 50 singlet and 3 triplet absorption transitions. All of the calculations were carried out as in acetonitrile by using a Polarizable Continuum Model (PCM). All calculations were carried out using the Gaussian $16 \mathrm{~W}$ package [20]. Molecular orbitals with the isovalue of 0.03 were drawn by the Gauss View $6[21]$.

\section{Supplementary material}

CCDC 1890891 contains the supplementary crystallographic data for this paper. This data can be obtained free of charge from The Cambridge Crystallographic Data Centre via www.ccdc.cam.ac.uk/data_request/cif. 


\section{Acknowledgements}

This work was partially supported by the JSPS KAKENHI Grant Numbers 15K05456 and 17K14463 and the Nippon Sheet Glass Foundation for Materials Science and Engineering.

\section{References}

[1] (a) K. Sakai, H. Ozawa, Coord. Chem. Rev. 251 (2007) 2753-2766.

(b) Q. Xu, W. F. Fu, G. Zhang, Z. Bian, J. Zhang, X. Han, W. Xu, Catal. Commun. 10 (2008) 49-52.

(c) P. Du, J. Schneider, P. Jarosz, R. Eisenberg, J. Am. Chem. Soc. 128 (2006) 77267727.

[2] (a) P. T. Furuta, L. Deng, S. Garon, M. E. Thompson, J. M. J. Fréchet, J. Am. Chem. Soc. 126 (2004) 15388-15389.

(b) P. K. Chow, G. Cheng, G. S. M. T. Ong, W. P. To, W. L. Kwong, C. C. Kowk, C. Ma, C. M. Che, Angew. Chem. Int. Ed. 54 (2015) 2084-2089.

(c) E. S. H. Lam, D. P. K. Tsang, W. H. Lam, A. Y. Y. Tam, M. Y. Chan, W. T. Wong, V. W. W. Yam, Chem. Eur. J. 19 (2013) 6385-6397.

(d) C. Cebrián, M. Mauro, D. Kourkoulos, P. Mercandelli, D. Hertel, K. Meerholz, C. A. Strassert, L. De Cola, Adv. Mater. 25 (2013) 437-442.

[3] (a) T. J. Wadas, Q. M. Wang, Y. J. Kim, C. Flaschenreim, T. N. Blanton, R. Eisenberg, J. Am. Chem. Soc. 126 (2004) 16841-16849.

(b) K. M. C. Wong, W. S. Tang, X. X. Lu, N. Zhu, V. W. W. Yam, Inorg. Chem. 44 (2005) 1492-1498.

(c) Q. Zhao, C. Huang, F. Li, Chem. Soc. Rev. 40 (2011) 2508-2524.

[4] (a) Y. Hong, J. W. Y. Lam, B. Z. Tang, Chem. Soc. Rev. 40 (2011) 5361-5388.

(b) C. Yu, K. H. Y. Chan, K. M. C. Wong, V. W. W. Yam, Chem. Commun. 0 (2009) 3756-3758.

(c) X. Yan, H. Wang, C. E. Hauke, T. R. Cook, M. Wang, M. L. Saha, Z. Zhou, M. Zhang, X. Li, F. Huang, P. J. Stang, J. Am. Chem. Soc. 137 (2015) 15276-15286.

(d) T. Ikeda, M. Takayama, J. Kumar, T. Kawai, T. Haino, Dalton Trans. 44 (2015) 13156-13162.

(e) S. S. Pasha, P. Alam, S. Dash, G. Kaur, D. Banerjee, R. Chowdhury, N. Rath, A. R. Choudhury, I.R. Laskar, RSC Adv. 4 (2014) 50549-50553.

[5] (a) P. Pinter, H. Mangold, I. Stengel, I. Münster, T. Strassner, Organometallics. 35 (2016) 673-680.

(b) B. W. D’Andrade, J. Brooks, V. Adamovich, M. E. Thompson, S. R. Forrest, Adv. 
Mater. 14 (2002) 1032-1036.

(c) X. Yang, Z. Wang, S. Madakuni, J. Li, G. E. Jabbour, Adv. Mater. 20 (2008) 24052409.

(d) B. Ma, P. I. Djurovich, S. Garon, B. Alleyne, M. E. Thompson, Adv. Funct. Mater. 16 (2006) 2438-2446.

[6] (a) B. Ma, J. Li, P. I. Djurovich, M. Yousufuddin, R. Bau, M. E. Thompson, J. Am. Chem. Soc. 127 (2005) 28-29.

(b) S. E. Brown-Xu, M. S. J. Kelley, K. A. Fransted, A. Chakraborty, G. C. Schatz, F.N. Castellano, L. X. Chen, J. Phys. Chem. A. 120 (2016) 543-550.

(c) C. Zhou, Y. Tian, Z. Yuan, M. Han, J. Wang, L. Zhu, M. S. Tameh, C. Huang, B. Ma, Angew. Chem. Int. Ed. 54 (2015) 9591-9595.

(d) C. Zhou, L. Yuan, Z. Yuan, N. K. Doyle, T. Dilbeck, D. Bahadur, S. Ramakrishnan, A. Dearden, C. Huang, B. Ma, Inorg. Chem. 55 (2016) 8564-8569.

(e) N. Ghavale, A. Wadawale, S. Dey, V. K. Jain, J. Organomet. Chem. 695 (2010) 1237-1245.

[7] (a) M. Tenne, S. Metz, G. Wagenblast, I. Münster, T. Strassner, Dalton Trans. 44 (2015) 8444-8455.

(b) S. Fuertes, H. García, M. Perálvarez, W. Hertog, J. Carreras, V. Sicilia, Chem. Eur. J. 21 (2015) 1620-1631.

(c) S. Fuertes, A. J. Chueca, M. Perálvarez, P. Borja, M. Torrell, J. Carreras, V. Sicilia, ACS Appl. Mater. Interfaces. 8 (2016) 16160-16169.

[8] (a) S. Ahrens, T. Strassner, Inorganica Chim. Acta. 359 (2006) 4789-4796.

(b) K. Li, X. Guan, C. W. Ma, W. Lu, Y. Chen, C. M. Che, Chem. Commun. 47 (2011) 9075-9077.

[9] M. Bachmann, D. Suter, O. Blacque, K. Venkatesan, Inorg. Chem. 55 (2016) 47334745.

[10] J. A. G. Williams, Photochemistry and Photophysics of Coordination Compounds: Platinum. In Photochemistry and Photophysics of Coordination Compounds II; V. Balzani, S. Campagna, Eds.; Springer: Berlin, 2007; Vol. 281, pp. 205-268.

[11] (a) K. Umakoshi, T. Kojima, K. Saito, S. Akatsu, M. Onishi, S. Ishizaka, N. Kitamura, Y. Nakao, S. Sakaki, Y. Ozawa, Inorg. Chem. 47 (2008) 5033-5035.

(b) K. Umakoshi, K. Saito, Y. Arikawa, M. Onishi, S. Ishizaka, N. Kitamura, Y. Nakao, S. Sakaki, Chem. Eur. J. 15 (2009) 4238-4242.

(c) K. Umakoshi, K. Kimura, Y. H. Kim, Y. Tsukimoto, Y. Arikawa, M. Onishi, S. Ishizaka, N. Kitamura, Bull. Chem. Soc. Jpn. 83 (2010) 1504-1510.

(d) S. Akatsu, Y. Kanematsu, T. A. Kurihara, S. Sueyoshi, Y. Arikawa, M. Onishi, S. 
Ishizaka, N. Kitamura, Y. Nakao, S. Sakaki, K. Umakoshi, Inorg. Chem. 51 (2012) 7977-7992.

(e) K. Nishihara, M. Ueda, A. Higashitani, Y. Nakao, Y. Arikawa, S. Horiuchi, E. Sakuda, K. Umakoshi, Dalton Trans. 45 (2016) 4978-4982.

(f) M. Ueda, S. Horiuchi, E. Sakuda, Y. Nakao, Y. Arikawa, K. Umakoshi, Chem. Commun. 53 (2017) 6405-6408.

(g) Horiuchi, S. Moon, E. Sakuda, A. Ito, Y. Arikawa, K. Umakoshi, Dalton Trans. 47 (2018) 7113-7117.

[12] Y. Chi, P. T. Chou, Chem. Soc. Rev. 39 (2010) 638-655.

[13] M. Kato, A. Omura, A. Toshikawa, S. Kishi, Y. Sugimoto, Angew. Chem. Int. Ed. 41 (2002) 3183-3185.

[14] A. Raba, M. R. Anneser, D. Jantke, M. Cokoja, W. A. Herrmann, F. E. Kühn, Tetrahedron Lett. 54 (2013) 3384-3387.

[15] S. Warsink, S. Bosman, J. J. Weigand, C. J. Elsevier, Appl. Organomet. Chem. 25 (2011) 276-282.

[16] P. Cao, J. Cabrera, R. Padilla, D. Serra, F. Rominger, M. Limbach, Organometallics. 31 (2012) 921-929.

[17] CrystalStructure 4.2: Crystal Structure Analysis Package, Rigaku Corporation, Tokyo, Japan 2000-2017.

[18] P. T. Beurskens, G. Beurskens, R. de Gelder, S. García-Granda, R. Israel, R. O. Gould, J. M. M. Smits, (1999). The DIRDIF99 Program System, Technical Report of the Crystallography Laboratory, University of Nijmegen, The Netherlands.

[19] SHELXL2014/7: G. M. Sheldrick, Acta Cryst. C71 (2015) 3-8.

[20] Gaussian 16, Revision A.03, M. J. Frisch, G. W. Trucks, H. B. Schlegel, G. E. Scuseria, M. A. Robb, J. R. Cheeseman, G. Scalmani, V. Barone, G. A. Petersson, H. Nakatsuji, X. Li, M. Caricato, A. V. Marenich, J. Bloino, B. G. Janesko, R. Gomperts, B. Mennucci, H. P. Hratchian, J. V. Ortiz, A. F. Izmaylov, J. L. Sonnenberg, D. Williams-Young, F. Ding, F. Lipparini, F. Egidi, J. Goings, B. Peng, A. Petrone, T. Henderson, D. Ranasinghe, V. G. Zakrzewski, J. Gao, N. Rega, G. Zheng, W. Liang, M. Hada, M. Ehara, K. Toyota, R. Fukuda, J. Hasegawa, M. Ishida, T. Nakajima, Y. Honda, O. Kitao, H. Nakai, T. Vreven, K. Throssell, J. A. Montgomery, Jr., J. E. Peralta, F. Ogliaro, M. J. Bearpark, J. J. Heyd, E. N. Brothers, K. N. Kudin, V. N. Staroverov, T. A. Keith, R. Kobayashi, J. Normand, K. Raghavachari, A. P. Rendell, J. C. Burant, S. S. Iyengar, J. Tomasi, M. Cossi, J. M. Millam, M. Klene, C. Adamo, R. Cammi, J. W. Ochterski, R. L. Martin, K. Morokuma, O. Farkas, J. B. Foresman, D. J. Fox, Gaussian, Inc., Wallingford CT, 2016. 
[21] Gauss View, Version 6, Roy Dennington, Todd A. Keith, and John M. Millam, Semichem Inc., Shawnee Mission, KS, 2016. 